Dinamika Kesehatan Jurnal Kebidanan dan Keperawatan Vol 10 No. 22019 ( ISSN: 2086-3454 EISSN: 2549-4058)

url: http://ojs.dinamikakesehatan.unism.ac.id DOI: https://doi.org/10.33859/dksm.v10i2

Pengaruh Edukasi Berbasis Keluarga Terhadap Pelaksanaan IMD Untuk Pencapaian ASI Ekslusif Untuk Optimalisasi Tumbuh Kembang Anak Pada Periode Emas

\title{
Pengaruh Edukasi Berbasis Keluarga Terhadap Pelaksanaan IMD Untuk Pencapaian ASI Ekslusif Untuk Optimalisasi Tumbuh Kembang Anak Pada Periode Emas
}

\author{
Tetti Seriati Situmorang1, Riska Susanti Pasaribu² \\ 1 Sekolah Tinggi Ilmu Kesehatan (STIKes) Mitra Husada Medan \\ 2 Sekolah Tinggi Ilmu Kesehatan (STIKes) Mitra Husada Medan \\ correspondence author: HP/WA: 081362184945,E-mail: seriatitetti@gmail.com
}

DOI: $\underline{\text { https://doi.org/10.33859/dksm.v10i2.493 }}$

\begin{abstract}
Abstrak
Latar Belakang: Pada periode emas sangat urgen dan efektif untuk dilakukannya optimalisasi berbagai aspek tumbuh kembang guna membentuk SDM berkualitas. Pada periode ini otak mengalami perkembangan paling cepat dalam sejarah kehidupannya yaitu hingga $80 \%$. ASI adalah makanan terbaik di awal kehidupan. Keberhasilan ASI Eksklusif berawal dari terlaksananya proses IMD. Lamanya waktu ASI keluar pada kali pertama menyusu menjadi penyebab terbesar kegagalan ASI Eksklusif. Diperburuk lagi dengan persepsi keluarga bahwa penyebab bayi menangis adalah karena ASI tidak keluar/tidak cukup sehingga perlu diberikan susu formula.

Tujuan: Penelitian ini bertujuan untuk mengidentifikasi pengaruh edukasi berbasis keluarga terhadap pelaksanaan IMD.

Metode: Desain penelitian menggunakan quasi experiment, pre test and post test with control group design. Diawali dengan melakukan pre test pada kedua kelompok responden, selanjutnya pada kelompok intervensi dilakukan edukasi berbasis keluarga (melibatkan suami/1 orang anggota keluarga lainnya) tentang IMD sebanyak 3 kali pertemuan. Tahap ketiga melakukan post test pada kedua kelompok. Jumlah responden sebnayak 40 orang masing-masing kelompok 20 ibu hamil. Analisis data menggunakan Wilcoxon test dan Mann whitney test.

Hasil: Hasil penelitian menunjukkan bahwa ada pengaruh yang signifikan antara edukasi berbasis keluarga terhadap pelaksanaan IMD ( $p$ value $=0.004)$.

Simpulan: Secara alamiah bayi baru lahir sehat dapat melakukan proses IMD, pengetahuan dan sikap ibu dan kelaurga perlu ditingkatkan. Disarankan penerapan edukasi berbasis keluarga terhadap pelaksanaan IMD untuk peningkatan pencapaian ASI Eksklusif
\end{abstract}

Kata Kunci: edukasi berbasis keluarga, IMD 


\section{Abstract}

Background: In the golden period, it was very urgent and effective to optimize various aspects of growth and development in order to form quality human resources. In this period the brain experiences the fastest development in its life history, which is up to $80 \%$. Breast milk is the best food in early life. The success of the exclusive ASI began with the implementation of the IMD process. The length of time that milk comes out the first time is the biggest cause of failure. To make matters worse, the family's perception that the cause of the baby crying is because the milk is not coming out / not enough so formula milk needs to be given.

Objective: This study aims to identify the effect of family-based education on the implementation of IMD.

Method: The research design uses quasi experiment, pre test and post test with control group design. It starts with a pre-test for the two groups of respondents, then in the intervention group a familybased education (involving husband / 1 other family member) about IMD is held 3 times. The third stage is to do a post test on both groups. The number of respondents was 40 people in each group of 20 pregnant women. Data analysis using Wilcoxon test and Mann Whitney test.

Results: The results showed that there was a significant influence between family-based education on the implementation of IMD ( $p$ value $=0.004$ ).

Conclusion: Naturally a healthy newborn can do the IMD process, knowledge and attitudes of the mother and family need to be improved. It is recommended that the application of family-based education to the implementation of IMD to increase the achievement of exclusive breastfeeding.

Key Words: family-based education, IMD

\section{Pendahuluan}

Periode emas tumbuh kembang anak berlangsung sejak anak dalam kandungan sampai berumur dua tahun. Pada periode ini sangat urgen dan efektif untuk dilakukannya optimalisasi berbagai aspek tumbuh kembang guna membentuk SDM berkualitas (Fakultas Kedokteran Universitas Hasanuddin, 2014). Pada periode ini otak mengalami perkembangan paling cepat dalam sejarah kehidupannya yaitu hingga $80 \%$. Pasca lahir sel saraf otak (berjumlah milyaran) tidak bertambah lagi namun jumlah hubungan antar sel saraf otak terus berlangsung. Satu sel saraf otak dapat menjalin hubungan dengan 20.000 sel saraf otak lainnya. Makin banyak jumlah hubungan sel saraf makin cerdas otak tersebut (Soetjiningsih, 2013). Besar jumlah hubungan antar sel syaraf otak ditentukan oleh nutrisi dan stimulasi. Kegagalan asupan nutrisi selama periode ini menimbulkan efek jangka panjang yang sulit bahkan yang tidak bisa diubah lagi (Arief, 2011). Masalah asupan gizi bayi di Sumatera Utara: bayi kurus yang mendapat 
Dinamika Kesehatan Jurnal Kebidanan dan Keperawatan Vol 10 No. 22019 ( ISSN: 2086-3454 EISSN: 2549-4058)

url: http://ojs.dinamikakesehatan.unism.ac.id DOI: https://doi.org/10.33859/dksm.v10i2

Pengaruh Edukasi Berbasis Keluarga Terhadap Pelaksanaan IMD Untuk Pencapaian ASI Ekslusif Untuk Optimalisasi Tumbuh Kembang Anak Pada Periode Emas

makanan tambahan $(36,7 \%)$. Cakupan ASI

Eksklusif $(33,0 \%)$, IMD $<1$ jam $(30,3 \%)$, menyusui sampai 5 bulan (48,6\%). Prevalensi gizi buruk dan gizi kurang berada diatas prevalensi nasional. Bayi dan balita usia 0-23 bulan terdapat gizi buruk (2,8\%), gizi kurang $(8,6 \%)$, usia $0-59$ bulan, gizi buruk $(3,1 \%)$, gizi kurang $(10,1 \%)$ (indikator BB/U). Status gizi dengan indeks TB/U menunjukkan angka kejadian stunting, pada: usia 0-23 bulan, sangat pendek $(8,0 \%)$, pendek $(11,1 \%)$, usia 0 59 bulan, sangat pendek $(9,3 \%)$, pendek $(15,1 \%)$. Status gizi dengan indeks BB/TB usia 0-23 bulan sangat kurus $(5,2 \%)$, kurus $(9,3 \%)$, usia 0-59 bulan sangat kurus (4,3\%), kurus (7,7\%). Stunting di awal kehidupan akan berdampak buruk pada kesehatan, kognitif, dan fungsional ketika dewasa (Dinkes Prov SU, 2017).

ASI adalah makanan terbaik di awal kehidupan (0-6 bulan), selanjutnya ASI ditambah makanan pendamping sampai usia dua tahun. Keberhasilan ASI Eksklusif berawal dari terlaksananya proses IMD (Juwono, 2016). Bayi yang menyusu dini akan berhasil menyusu eksklusif delapan kali lebih besar dibandingkan bayi yang tidak menyusu dini (Dinkes Prov SU, 2017).

Cakupan ASI Eksklusif Puskesmas Namo Rambe (40\%). Lamanya waktu ASI keluar pada kali pertama menyusu menjadi penyebab terbesar $(>50 \%)$ kegagalan IMD. Diperburuk lagi dengan persepsi keluarga/masyarakat bahwa penyebab bayi menangis setelah disusui adalah karena ASI tidak cukup sehingga perlu diberikan susu formula (Profil Kesehatan Puskesmas namo Rambe , 2017). Program Indonesia sehat dengan pendekatan keluarga menyatakan bahwa pendekatan keluarga adalah kunci keberhasilan program tersebut. Edukasi berbasis keluarga dapat meningkatkan intensi untuk mengubah perilaku kesehatan (Kemenkes, RI, 2016). Intervensi edukasi berbasis keluarga tentang IMD untuk pencapaian ASI Eksklusif untuk optimalisasi tumbuh kembang anak pada periode emas perlu dilakukan. 
Dinamika Kesehatan Jurnal Kebidanan dan Keperawatan Vol 10 No. 22019 ( ISSN: 2086-3454 EISSN: 2549-4058)

url: http://ojs.dinamikakesehatan.unism.ac.id DOI: https://doi.org/10.33859/dksm.v10i2

Pengaruh Edukasi Berbasis Keluarga Terhadap Pelaksanaan IMD Untuk Pencapaian ASI Ekslusif Untuk Optimalisasi Tumbuh Kembang Anak Pada Periode Emas

\section{Bahan dan Metode}

Penelitian ini merupakan penelitian kuantitatif dengan menggunakan quasi experiment pre test and post test with control group design, untuk menganalisa pengaruh edukasi berbassis keluarga terhadap pelaksanaan IMD. Kelompok intervensi akan menerima edukasi berbasis keluarga terkait manajemen laktasi dan kelompok kontrol menerima edukasi dari petugas kesehatan saat melakukan pemeriksaan Antenatal Care (pemeriksaan kehamilan) di Puskesmas. Sebelum dilakukan intervensi, pada kelompok intervensi dan kelompok kontrol dilakukan pre test, kemudian dilaksanakan edukasi berbasis keluarga. Setelah 3 bulan kegiatan edukasi berbasis keluarga dilaksanakan, kemudian dilakukan post test pada kedua kelompok dengan instrument kuesioner yang sama dengan pre test

\section{Hasil}

\section{Analisis Univariat}

\section{A. Karakteristik responden}

Sampel dalam penelitian ini sebanyak 40 orang terdiri dari 2 kelompok yaitu 20 orang ibu hamil usia kehamilan 24-28 minggu yang diberikan edukasi berbasis keluarga tentang inisiasi menyusu dini (IMD) yang merupakan kelompok intervensi dan 20 orang ibu hamil dengan rentag usia kehamilan yang sama tidak diberikan edukasi berbasis keluarga tentang IMD yang merupakan kelompok control

Tabel 1. Distribusi Frekuensi Karakteristik Responden

\begin{tabular}{|c|c|c|c|c|c|c|c|}
\hline \multirow[t]{3}{*}{$\begin{array}{l}\mathbf{N} \\
\mathbf{0}\end{array}$} & \multirow[t]{3}{*}{ Karakteristik } & \multicolumn{4}{|c|}{$\begin{array}{c}\text { Kelompok } \\
(n=40)\end{array}$} & \multirow{2}{*}{\multicolumn{2}{|c|}{$\begin{array}{c}\text { Total } \\
\mathbf{n}\end{array}$}} \\
\hline & & \multicolumn{2}{|c|}{$\begin{array}{c}\text { Interv } \\
\text { ensi }\end{array}$} & \multicolumn{2}{|c|}{$\begin{array}{c}\text { Kontr } \\
\text { ol }\end{array}$} & & \\
\hline & & $\mathbf{n}$ & $\%$ & n & $\%$ & $\mathbf{n}$ & $\%$ \\
\hline 1 & $\begin{array}{l}\text { Umur: } \\
-<20 \text { tahun } \\
-20-35 \text { tahun } \\
->35 \text { tahun } \\
\quad \text { Total }\end{array}$ & $\begin{array}{l}1 \\
1 \\
7 \\
2 \\
2 \\
2 \\
0\end{array}$ & $\begin{array}{l}5 \\
85 \\
10 \\
10 \\
0\end{array}$ & $\begin{array}{l}- \\
1 \\
8 \\
2 \\
2 \\
0\end{array}$ & $\begin{array}{l}- \\
90 \\
10 \\
10 \\
0\end{array}$ & $\begin{array}{l}1 \\
3 \\
5 \\
4 \\
4 \\
0\end{array}$ & $\begin{array}{l}2 . \\
5 \\
87 \\
.5 \\
10 \\
10 \\
0 \\
\end{array}$ \\
\hline 2 & $\begin{array}{l}\text { Pendidikan: } \\
\text { - SD } \\
\text { - SMP } \\
\text { - SMA } \\
\text { - PT } \\
\text { - Total }\end{array}$ & $\begin{array}{l}2 \\
5 \\
7 \\
6 \\
2 \\
0\end{array}$ & $\begin{array}{l}10 \\
25 \\
35 \\
30 \\
10 \\
0\end{array}$ & $\begin{array}{l}- \\
3 \\
1 \\
0 \\
7 \\
2 \\
0\end{array}$ & $\begin{array}{l}- \\
15 \\
50 \\
35 \\
10 \\
0\end{array}$ & $\begin{array}{l}2 \\
8 \\
1 \\
7 \\
1 \\
3 \\
4 \\
0\end{array}$ & $\begin{array}{l}5 \\
20 \\
42 \\
5 \\
32 \\
5 \\
10 \\
0\end{array}$ \\
\hline 3 & $\begin{array}{l}\text { Pekerjaan: } \\
\text { - Ibu Rumah } \\
\text { Tangga (IRT) } \\
\text { - PNS } \\
\text { - Pegawai } \\
\text { Swasta } \\
\text { - Wiraswasta } \\
\text { Total }\end{array}$ & $\begin{array}{l}1 \\
6 \\
1 \\
3 \\
- \\
2 \\
0\end{array}$ & $\begin{array}{l}80 \\
5 \\
15 \\
- \\
10 \\
0\end{array}$ & $\begin{array}{l}1 \\
2 \\
1 \\
4 \\
3 \\
2 \\
0\end{array}$ & $\begin{array}{l}60 \\
5 \\
20 \\
15 \\
10 \\
0\end{array}$ & $\begin{array}{l}2 \\
8 \\
2 \\
7 \\
3 \\
3 \\
4 \\
0\end{array}$ & $\begin{array}{r}70 \\
5 \\
17 \\
.5 \\
\\
7 . \\
5 \\
10 \\
0\end{array}$ \\
\hline 4 & $\begin{array}{l}\text { Paritas: } \\
-\quad 1 \\
-\quad 2 \\
-\quad 3 \\
-\quad 4 \\
\quad \text { Total }\end{array}$ & $\begin{array}{l}6 \\
1 \\
0 \\
4 \\
- \\
2 \\
0\end{array}$ & $\begin{array}{l}30 \\
50 \\
20 \\
- \\
10 \\
0\end{array}$ & $\begin{array}{l}8 \\
6 \\
4 \\
2 \\
2 \\
0\end{array}$ & $\begin{array}{l}40 \\
30 \\
20 \\
10 \\
10 \\
0\end{array}$ & $\begin{array}{l}1 \\
4 \\
1 \\
6 \\
8 \\
2 \\
4 \\
0\end{array}$ & $\begin{array}{r}35 \\
40 \\
20 \\
5 \\
10 \\
0\end{array}$ \\
\hline
\end{tabular}

Pada karakteristik umur pada kedua kelompok didominasi oleh umur 20-35 tahun yaitu sebesar $85 \%$ pada kelompok intervensi dan 90 \% pada kelompok kontrol. Demikian pula pada 
Dinamika Kesehatan Jurnal Kebidanan dan Keperawatan Vol 10 No. 22019 ( ISSN: 2086-3454 EISSN: 2549-4058)

url: http://ojs.dinamikakesehatan.unism.ac.id DOI: https://doi.org/10.33859/dksm.v10i2

Pengaruh Edukasi Berbasis Keluarga Terhadap Pelaksanaan IMD Untuk Pencapaian ASI Ekslusif Untuk Optimalisasi Tumbuh Kembang Anak Pada Periode Emas

karakteristik pendidikan, pada kedua

kelompok didominasi oleh pendidikan SMA

yaitu sebesar $35 \%$ pada kelompok intervensi dan 50\% pada kelompok kontrol. Pada karakteristik pekerjaan juga ditemukan hal yang sama, karakteristik ini didominasi oleh IRT sebesar $80 \%$ pada kelompok intervensi dan sebesar $60 \%$ pada kelompok kontrol. Pada karakteristik paritas terdapat perbedaan, pada kelompok intervensi didominasi oleh paritas 2 sebesar 50\%, pada kelompok kontrol didominasi oleh paritas 1 sebesar $40 \%$.

Hasil Pre Test Pengetahuan dan Sikap Responden Tabel 2. Distibusi Frekuensi Pre Test Pengetahuan dan Sikap pada Kelompok Intervensi dan Kelompok Kontrol

\begin{tabular}{|c|c|c|c|c|c|c|c|}
\hline \multirow[t]{3}{*}{$\begin{array}{l}\mathbf{N} \\
\mathbf{0}\end{array}$} & \multirow[t]{3}{*}{$\begin{array}{c}\text { Variab } \\
\text { el }\end{array}$} & \multicolumn{4}{|c|}{$\begin{array}{c}\text { Kelompok } \\
(n=40)\end{array}$} & \multirow{2}{*}{\multicolumn{2}{|c|}{ Total n }} \\
\hline & & \multicolumn{2}{|c|}{$\begin{array}{c}\text { Interv } \\
\text { ensi }\end{array}$} & \multicolumn{2}{|c|}{$\begin{array}{c}\text { Kontro } \\
1\end{array}$} & & \\
\hline & & n & $\%$ & $\mathbf{n}$ & $\%$ & n & $\%$ \\
\hline \multirow[t]{6}{*}{1} & Pengeta & & & & & & \\
\hline & huan: & 8 & 40 & 6 & 30 & 14 & 35 \\
\hline & - Baik & 1 & 60 & 14 & 70 & 26 & 65 \\
\hline & - Kura & 2 & 10 & 20 & 10 & 40 & 10 \\
\hline & ng & 2 & 0 & & 0 & & 0 \\
\hline & Total & 0 & & & & & \\
\hline \multirow[t]{6}{*}{2} & Sikap: & & & & & & \\
\hline & - Positi & 8 & 40 & 6 & 30 & 14 & 35 \\
\hline & f & 1 & 60 & 14 & 70 & 26 & 65 \\
\hline & - Nega & 2 & 10 & 20 & 10 & 40 & 10 \\
\hline & tif & 2 & 0 & & 0 & & 0 \\
\hline & Total & 0 & & & & & \\
\hline
\end{tabular}

Persentase kategori pengetahuan yang baik dan sikap yang positif pada kelompok intervensi lebih besar dibanding dengan kelompok kontrol. Persentase kategori pengetahuan yang baik dan sikap yang positif pada kelompok intervensi sama besar yaitu $40 \%$, persentase kategori pengetahuan yang baik dan sikap yang positif pada kelompok kontrol juga sama besar yaitu $30 \%$.

Hasil Post Test Pengetahuan dan Sikap Responden

Tabel 3. Distribusi Frekuensi Post Test Pengetahuan dan Sikap pada kelompok Intervensi dan Kelompok Kontrol

\begin{tabular}{|c|c|c|c|c|c|c|c|}
\hline \multirow[t]{3}{*}{$\begin{array}{l}\mathbf{N} \\
\mathbf{o}\end{array}$} & \multirow[t]{3}{*}{$\begin{array}{c}\text { Variabe } \\
1\end{array}$} & \multicolumn{4}{|c|}{$\begin{array}{c}\text { Kelompok } \\
(\mathrm{n}=\mathbf{4 0})\end{array}$} & \multicolumn{2}{|c|}{ Total $\mathbf{n}$} \\
\hline & & \multicolumn{2}{|c|}{$\begin{array}{c}\text { Interv } \\
\text { ensi }\end{array}$} & \multicolumn{2}{|c|}{ Kontrol } & \multirow[b]{2}{*}{$\mathbf{n}$} & \multirow[b]{2}{*}{$\%$} \\
\hline & & $\mathrm{n}$ & $\%$ & $\mathbf{n}$ & $\%$ & & \\
\hline \multirow[t]{6}{*}{1} & Pengeta & & & & & & \\
\hline & huan: & 1 & 85 & 4 & 20 & 21 & 52. \\
\hline & - Baik & 7 & 5 & 16 & 80 & 19 & 5 \\
\hline & - Kuran & 3 & 10 & 20 & 10 & 40 & 47. \\
\hline & $\mathrm{g}$ & 2 & 0 & & 0 & & 5 \\
\hline & Total & 0 & & & & & 100 \\
\hline \multirow[t]{6}{*}{2} & Sikap: & & & & & & \\
\hline & - Positif & 1 & 90 & 5 & 25 & 23 & 57. \\
\hline & - Negat & 8 & 10 & 15 & 75 & 17 & 5 \\
\hline & if & 2 & 10 & 20 & 10 & 40 & 42. \\
\hline & Total & 2 & 0 & & 0 & & 5 \\
\hline & & 0 & & & & & 100 \\
\hline
\end{tabular}

peningkatan pengetahuan dan sikap yang signifikan pada kelompok intervensi, sedangkan pada kelompok kontrol tidak ada peningkatan pengetahuan dan sikap positif terhadap pelaksanaan IMD 
Dinamika Kesehatan Jurnal Kebidanan dan Keperawatan Vol 10 No. 22019 ( ISSN: 2086-3454 EISSN: 2549-4058)

url: http://ojs.dinamikakesehatan.unism.ac.id DOI: https://doi.org/10.33859/dksm.v10i2

Pengaruh Edukasi Berbasis Keluarga Terhadap Pelaksanaan IMD Untuk Pencapaian ASI Ekslusif Untuk Optimalisasi Tumbuh Kembang Anak Pada Periode Emas

Pelaksanaan IMD pada Kelompok Intervensi

dan Kelompok Kontrol

Tabel 4. Pelaksanaan IMD pada Kelompok Intervensi dan Kelompok Kontrol

\begin{tabular}{llcccc}
\hline \multirow{2}{*}{ No } & Pelaksanaan IMD & \multicolumn{2}{c}{$\begin{array}{c}\text { Kelompok } \\
\text { Intervensi }\end{array}$} & \multicolumn{2}{c}{$\begin{array}{c}\text { Kelompok } \\
\text { Kontrol }\end{array}$} \\
\cline { 2 - 6 } & & $\mathbf{N}$ & $\mathbf{\%}$ & $\mathbf{N}$ & $\%$ \\
\hline 1 & Dilaksanakan & 12 & 60 & 3 & 15 \\
\hline 2 & $\begin{array}{l}\text { Tidak } \\
\text { dilaksanakan }\end{array}$ & 8 & 40 & 17 & 85 \\
\hline \multicolumn{2}{l}{ Total } & 20 & 100 & 20 & 100 \\
\hline Persentase kelompok & intervensi & yang
\end{tabular}

melakukan IMD lebih besar hingga empat kali

dibandingkan dengan kelompok kontrol.

1. Analisis Bivariat

Perbedaan Pengetahuan Dan Sikap Pre Test Dan Post Test Pada Kelompok Kontrol

Tabel 5. Hasil uji perbedaan pengetahuan dan sikap pre test dan post test pada kelompok

kontrol menggunakan Wilcoxon test.

\begin{tabular}{lcccc}
\hline \multirow{2}{*}{ Variabel } & Pre Test & $\begin{array}{l}\text { Post } \\
\text { Test }\end{array}$ & Z-Test & p value \\
\cline { 2 - 4 } & Mean & $\begin{array}{c}\text { Mean } \\
\text { Runk }\end{array}$ & & \\
\hline Pengetahuan & 2,00 & 2,00 & $-0,577$ & 0,564 \\
\hline Sikap & 2,00 & 2,00 & $-0,577$ & 0,564 \\
\hline Data tabel & diatas & menggambarkan & uji
\end{tabular}

perbedaan pengetahuan dan sikap pre test dan

post test pada kelompok kontrol menggunakan

Wilcoxon test. Diketahui nilai $p$ value pada

variabel pengetahuan dan sikap $0,564(>0,05)$

artinya tidak ada perbedaan bermakna pada

variabel pengetahuan dan variabel sikap pada

pre test dan post test pada kelompok kontrol.
Perbedaan Pengetahuan Dan Sikap Pre Test

Dan Post Test Pada Kelompok Intervensi

Tabel 6. Hasil uji perbedaan pengetahuan dan sikap pre test dan post test pada kelompok intervensi menggunakan Wilcoxon test.

\begin{tabular}{lcccc}
\hline \multirow{4}{*}{ Variabel } & $\begin{array}{c}\text { Pre } \\
\text { Test }\end{array}$ & $\begin{array}{c}\text { Post } \\
\text { Test }\end{array}$ & & \\
\cline { 2 - 4 } & Mean & Zean & & Z value \\
& Runk & Runk & & \\
\hline Pengetahuan & 0.00 & 5,00 & $-3,000$ & 0,003 \\
& & & & \\
\hline Sikap & 0,00 & 5,50 & $-3,162$ & 0,002 \\
& & & & \\
\hline
\end{tabular}

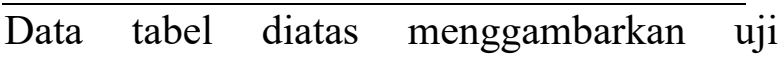

perbedaan pengetahuan dan sikap pre test dan post test pada kelompok intervensi menggunakan Wilcoxon test. Diketahui nilai $p$ value pada variabel pengetahuan 0,003 dan sikap $0,002(<0,05)$ artinya ada perbedaan bermakna pada variabel pengetahuan dan variabel sikap pada pre test dan post test pada kelompok intervensi sebelum dan sesudah diberikan edukasi berbasis keluarga tentang IMD.

Perbedaan Pelaksanaan IMD Pada Kelompok Kontrol dan Intervensi

Tabel 7. Hasil uji perbedaan pelaksanaan IMD pada kelompok kontrol dan intervensi menggunakan Mann Whitney Test.

\begin{tabular}{|c|c|c|c|c|}
\hline \multirow{2}{*}{ Variabel } & Kontrol & $\begin{array}{c}\text { Interve } \\
\text { nsi }\end{array}$ & \multirow{2}{*}{ Z-Test } & \multirow{2}{*}{$p$ value } \\
\hline & $\begin{array}{l}\text { Mean } \\
\text { Runk }\end{array}$ & $\begin{array}{l}\text { Mean } \\
\text { Runk }\end{array}$ & & \\
\hline $\begin{array}{l}\text { Pelaksanaan } \\
\text { IMD }\end{array}$ & 16,00 & 25,00 & $-2,902$ & 0,004 \\
\hline
\end{tabular}


Dinamika Kesehatan Jurnal Kebidanan dan Keperawatan Vol 10 No. 22019 ( ISSN: 2086-3454 EISSN: 2549-4058)

url: http://ojs.dinamikakesehatan.unism.ac.id DOI: https://doi.org/10.33859/dksm.v10i2

Pengaruh Edukasi Berbasis Keluarga Terhadap Pelaksanaan IMD Untuk Pencapaian ASI Ekslusif Untuk Optimalisasi Tumbuh Kembang Anak Pada Periode Emas

kontrol dan intervensi menggnakan Mann

Whitney Test. Diketahui nilai $p$ value 0,004 (<

0,005) artinya ada perbedaan bermakna

pelaksanaan IMD pada kelompok kontrol dan

intervensi. Dengan demikian dapat

disimpulkan bahwa ada pengaruh edukasi

berbasis keluarga tentang IMD terhadap

pelaksanaan IMD untuk pencapaian ASI

Eksklusif untuk optimalisasi tumbuh kembang anak pada periode emas.

\section{Pembahasan}

Hasil penelitian memberikan hasil

bahwa edukasi berbasis keluarga mampu

meningkatkan pengetahuan ibu hamil tentang

IMD dari 8 orang $(40 \%)$ dengan tingkat

pengetahuan baik menjadi 17 orang $(85 \%)$, terjadi peningkatan sebesar $45 \%$. Demikian pula dengan perubahan sikap negatif menjadi positif yang meningkat dari 8 orang (40\%) menjadi $18(90 \%)$, meningkat sebesar 50\%. Berbeda dengan kelompok ibu hamil yang tidak mendapat perlakukan edukasi berbasis keluarga tentang IMD yang tidak mengalami pengingkatan pengetahan dan perubahan sikap, malah mengalami penurunan. Aspek pengetahuan dari 6 orang (30\%) orang dengan tingkat pengetahuan baik pada pre test menjadi 4 orang (20\%), terjadi penurunan sebesar $10 \%$. Aspek sikap yang semula 6 orang (30\%) menurun sebesar $5 \%$ menjadi 5 orang $(25 \%)$.

Pengetahuan adalah hasil tahu, yang akan terjadi setelah seseorang melakukan penginderaan terhadap suatu objek tertentu, seperti melihat, mendengar, mencium, merasa dan meraba. Sebagian besar pengetahuan itu diperoleh melalui hasil melihat dan mendengar. Salah satu strategi untuk perubahan pengetahuan dan sikap adalah pemberian informasi guna meningkatakan pengetahuan sehingga timbul kesadaran dan pada akhirnya orang akan berperilaku sesuai dengan pengetahuannya tersebut. Perubahan sikap pada dasarnya dipengaruhi oleh faktor pengetahuan dan keyakinan/kepercayaan yang di dapatkan dari proses belajar. Setelah ibu dan keluarga mendapat edukasi, membaca informasi tentang IMD, pengetahuan ini akan membawa ibu berfikir, berkeinginan dan berusaha agar bayinya saat lahir kelak mengalami proses IMD. Setelah ibu 
Dinamika Kesehatan Jurnal Kebidanan dan Keperawatan Vol 10 No. 22019 ( ISSN: 2086-3454 EISSN: 2549-4058)

url: http://ojs.dinamikakesehatan.unism.ac.id DOI: https://doi.org/10.33859/dksm.v10i2

Pengaruh Edukasi Berbasis Keluarga Terhadap Pelaksanaan IMD Untuk Pencapaian ASI Ekslusif Untuk Optimalisasi Tumbuh Kembang Anak Pada Periode Emas

mengetahui stimulus, 1 proses selanjutnya

adalah bersikap terhadap terhadap stimulus

tersebut. Aspek yang memiliki peranan penting terhadap manifestasi sikap secara utuh adalah pengetahuan, pikiran, keyakinan da emosi (Notoatmodjo, 2007). Terlaksananya IMD pada saat bayi baru lahir tidak hanya dipengaruhi oleh perilaku ibu, peran suami dan atau anggota keluarga serta tenaga kesehatan yang terlibat dalam pertolongan proses persalinan ibu sangat menentukan. Dari hasil pengamata masih banyak tenaga kesehatan yang belum melaksanakan IMD. Setelah bayi lahir dikeringkan, ditimbang, dibedong lalu diberikan kepada ibu atau dipindahkan ke ruang bayi. Ibu dan suami atau anggota keluarga lainnya yang telah mendapatkan edukasi tentang IMD menanyakan informasi dan meminta kesediaan tenaga kesehatan yang akan menolong persalinan responden untuk melakukan IMD.

Hal ini sejalan dengan penelitian yang dilakukan oleh (Naim, 2017) yang menyatakan ada pengaruh yang signifikan antara edukasi berbasis keluarga terhadap intensi ibu hamil untuk optimalisasi nutrisi pada 1000 hari pertama kehidupan. Bayi yang lahir sehat tidak perlu mendapat bantuan untuk melakukan proses IMD. Secara alamiah bayi baru lahir memiliki reflex olfaktori (penciuman) dan visual yaitu bayi mampu mengenali areola dan bau khas payudara ibu. Selain itu faktor lain yang memudahkan proses IMD adalah bahwa bayi baru lahir memiliki refleks mencari dan menghisap putting susu ibu. Fakta ini meningkatkan optimisme ibu dan atau anggota keluarga untuk melakukan proses IMD saat bersalin.

\section{Ucapan Terima Kasih}

1. Kepada Kementerian Riset Teknologi dan Pendidikan Tinggi yang telah mendanai penelitian ini

2. Kepada Ketua pengurus Yayasan Mitra Husada dan jajarannya yang telah memberi kesempatan dan rekomendasi pada pengusulan hingga pelaksanaan penelitian ini.

3. Kepada pimpinan Puskesmas Namo Rambe Kabupaten Deli Serdang dan jajarannya yang telah memberikan ijin dan selalu 
Dinamika Kesehatan Jurnal Kebidanan dan Keperawatan Vol 10 No. 22019 ( ISSN: 2086-3454 EISSN: 2549-4058)

url: http://ojs.dinamikakesehatan.unism.ac.id DOI: https://doi.org/10.33859/dksm.v10i2

Pengaruh Edukasi Berbasis Keluarga Terhadap Pelaksanaan IMD Untuk Pencapaian ASI Ekslusif Untuk Optimalisasi Tumbuh Kembang Anak Pada Periode Emas

membantu pelaksanaan penelitian di lokasi ini.

4. Kepada timwork UUPM dan timwork penelitian ini yang telah bekerja sama dan sama-sama bekerja.

5. Kepada keluarga kami yang selalu mengasihi dan mendoakan peneliti.

\section{Daftar Pustaka}

Fakultas Kedokteran Universitas Hasanuddin. (2014) Buku Pedoman 1000 Hari Awal Kehidupan.

Soetjiningsih. (2013). Tumbuh Kembang Anak. Jakarta: Buku Kedokteran EGC.

Arief, N. (2011). Panduan Ibu Cerdas ASI dan Tumbuh kembang Bayi. Yogyakarta: MedPress.

Dinas Kesehatan Provinsi Sumatera Utara. (2017) Profil Kesehatan Provinsi Sumatera Utara Tahun 2016. Medan.

Juwono, L. (2016). Menyussui: Cara Mudah, Praktis dan Aman. Jakarta: Arcan.

Puskesmas Namo Rambe .(2018). Profil Kesehatan Puskesmas Namo Rambe Tahun 2017. Kecamatan Namo Rambe.

Kemenkes RI. (2016). Pedoman Umum Program Indonesia Sehat Dengan Pendekatan Keluarga. Jakarta: Kemenkes RI.

Roesli, U. (2012). Panduan Inisisasi Menyusu Dini Plus ASI Eksklusif. Depok: Pustaka Bunda.

Novianti, R. (2012). Menyusui Itu Indah. Yogyakarta: Octopus.

Widianto, G \& Rostiawati, Y.(2016). Cara Menyusui Yang Baik. Jakarta: Arcan.
Hani'ah, M.(2014). Buku Pintar ASI Eksklusif. Yogyakarta: DIVA Press

Sulistyoningsih, H. (2011). Gizi Untuk Kesehatan Ibu dan Anak. Yogyakarta: Graha Ilmu.

Mulyani, S, N. (2013).ASI dan Panduan Ibu Menyusui.Yogyakarta: Nuha Medika.

Soetjiningsih. (2012). ASI: Petunjuk Untuk Tenaga Kesehatan. Jakarta: Buku Kedokteran EGC.

Friedman, M. (2015). Keperawatan Keluarga: Teori dan Praktik.Jakarta: Buku Kedokteran EGC.

Aziz, S. (2015). Pendidikan Keluarga; Konsep dan Strategi.Yogyakarta: GAVA Media.

Pedoman Perencanaan Program Gerakan Nasional Percepatan Perbaikan Gizi Dalam Rangka Seribu Hari Pertama Kehidupan (Gerakan 1000 HPK) RI (2013).

Jaringan Nasional Pelatihan Klinik- Kesehatan Reproduksi. (2012). Inisiasi Menyusu Dini.

Notoatmodjo, S, 2007, Ilmu Perilaku Kesehatan. Jakarta: Rineka Cipta.

Naim, R. 2007, edukasi berbasis keluarga terhadap intensi ibu hamil untuk optimalisasi nutrisi pada 1000 hari pertama kehidupan. http://jkp.fkep.unpad.ac.id/index.php/jk p/article/view/475/166 